\title{
Primary Care for Women with Intellectual Disabilities
}

\author{
Joanne E. Wilkinson, MD, MSc, and Mary C. Cerreto, PhD
}

Women with intellectual disabilities (ID) need thoughtful, well-coordinated care from primary care physicians. They are particularly susceptible to experiencing disparities in care because of varied participation in shared decision making. This review of the current literature comments on the quantity and quality of existing studies regarding several key women's health issues: menstrual disorders, cervical and breast cancer screening, contraception, and osteoporosis. A review of the current thinking regarding ethical and legal issues in medical decision making for these women is also provided. We found that there are several high-quality studies recommending early and frequent screening for osteoporosis, which is more common in women with ID. Smaller and fewer studies comment specifically on techniques for accomplishing the gynecological examination in women with ID, although the cervical cancer screening recommendation should be individualized for these patients. Consensus data on the management of menstrual problems and contraception in women with ID is provided. There are some data on breast cancer incidence but few articles on methods to improve screening rates in women with ID. (J Am Board Fam Med 2008;21:215-222.)

Intellectual disability (ID) refers to a disability that is characterized by significant limitations both in cognitive functioning and in adaptive behavior (conceptual, social, and practical skills) that originate before age $18 .{ }^{1}$ This term (intellectual disability) is synonymous with the term "mental retardation" in this article. Many people with ID dislike this term, viewing it as stigmatizing and a stereotyping label for complex people with a wide range of abilities. Adults with ID now live longer because of improved medical and environmental conditions. $^{2}$ They more likely live in community-based settings rather than in large, segregated institutions. These changes shift the focus of their medical care to the outpatient, primary care setting, with an emphasis on prevention of morbidity and mortality later in life. ${ }^{3}$ Two recent important doc-

This article was externally peer reviewed.

Submitted 25 August 2007; revised 5 November 2007; accepted 3 December 2007.

From the Department of Family Medicine, Boston University School of Medicine, Massachusettes.

Funding: none.

Conflict of interest: none declared.

Corresponding author: Joanne E. Wilkinson, MD, MSc, Department of Family Medicine, Dowling 5, 840 Harrison Avenue, Boston, MA 02118 (E-mail: Joanne.Wilkinson@ bmc.org). uments, Healthy People 2010 and Closing the Gap, ${ }^{4,5}$ stress the importance of eliminating health disparities for people with ID, especially through primary care and prevention.

Women's health issues are important concerns among those with ID. In the past 40 years, it has been suggested that women's health should shift to a focus tailored to the individual patient, taking into account her personal beliefs and respecting her choices. The preface to the 1984 edition of Our Bodies, Our Selves states its goals "to reach as many women as possible with the tools which will enable them to take greater charge of their own health care and their lives, deal with the existing medical system and fight wherever possible for improvements and changes." While physicians' responsibilities to regard women as equal partners in making decisions about their health care has been debated, ${ }^{7}$ patients' reproductive rights and choices have remained an important topic of discussion. Women with ID, however, benefit unevenly from this change in thinking. It is unclear how women who may lack some of the skills to make everyday decisions should partner in decisions about their health care. In addition, in a field where research has lagged on women's health topics, how do we interpret the existing evidence base for women with 


\begin{tabular}{|c|c|c|c|c|c|}
\hline $\begin{array}{l}\text { Search Terms: "Mental Retardation" } \\
\text { OR "Intellectual Disability" AND }\end{array}$ & $\begin{array}{c}\text { Number of } \\
\text { Articles Identified }\end{array}$ & $\begin{array}{l}\text { Basic Science } \\
\text { or Case Reports }\end{array}$ & Other* & $\begin{array}{l}\text { Final Number } \\
\text { Reviewed }\end{array}$ & $\begin{array}{l}\text { Final Number } \\
\text { Used }\end{array}$ \\
\hline $\begin{array}{l}\text { "Contraception" OR "Contraception } \\
\text { behavior" OR "Menstrual disorders" } \\
\text { OR "Amenorrhea" }\end{array}$ & 65 & $6^{\dagger}$ & 46 & 13 & 11 \\
\hline $\begin{array}{l}\text { "Pap Smear" OR "Cervical Cancer" OR } \\
\text { "Gynecological Exam" }\end{array}$ & 14 & 5 & 5 & 4 & $8^{\ddagger}$ \\
\hline $\begin{array}{l}\text { "Mammography" OR "Breast disease" } \\
\text { OR "Breast neoplasm" }\end{array}$ & 21 & 11 & 5 & 5 & $7^{\S}$ \\
\hline $\begin{array}{l}\text { "Osteoporosis" OR "Bone density" OR } \\
\text { "Bone densitometry" }\end{array}$ & 127 & 44 & 67 & 16 & $13^{\|}$ \\
\hline
\end{tabular}

*Other reasons for exclusion include: population included other forms of cognitive disability (eg, dementia); population included men or children; syndrome-specific (except for Down syndrome); not in English/not translated.

${ }^{\dagger}$ In this category only, articles published before 1985 were eliminated, as contraceptive recommendations and options for the general population have changed substantively since that time.

${ }^{\ddagger}$ Includes 4 articles from nursing journals which describe techniques for the gynecological exam in women with intellectual disabilities. These were identified from the bibliography of ref. 8 .

SIncludes 3 additional articles from ref. 8.

"Includes 1 additional article from ref. 8.

ID? The following review addresses 5 important topics in women's health (menstrual disorders, cervical cancer screening, contraception, breast cancer screening, and osteoporosis) as they apply specifically to women with ID and interprets the most up-to-date recommendations in light of the current ethical thinking regarding the rights of adults with ID.

\section{Methods}

For this review, we searched Ovid/Medline using each term in combination ("mental retardation" OR "intellectual disability" plus [the name of the condition or topic]) to generate initial lists of articles. These abstracts were reviewed and articles excluded if they were not available in English, pertained only to children or men and not adult women, were case studies, or were descriptions of scientific research unrelated to clinical medicine. The remaining articles were reviewed in more detail and those focusing on prevalence, screening, diagnosis, and treatment in the clinical setting were included in this review (Table 1). Articles were also reviewed from the bibliography of a recent textbook in the field. ${ }^{8}$ For the ethics section, one author (MCC) searched the literature based on expert opinion. Both authors conducted independent reviews to select articles appropriate for inclusion in this summary. Of 173 articles identified, 32 were used in this article. When available, general guidelines or references for clinical care are provided (via consensus statements).

\section{Results}

\section{Menstrual Disorders}

For most women in the general population, menstrual disorders include the management of dysmenorrhea, amenorrhea, and menorrhagia, which are most often related to anovulatory cycles but also to uterine disorders such as fibroids. For women with ID, another issue can be added to this category: the inability to manage menstrual hygiene and the risk of self-injurious behaviors that can arise around menstruation. These issues have prompted, in some cases, the inducement of elective or therapeutic amenorrhea.

Reasons for therapeutic amenorrhea may include contraception (especially if the patient is taking teratogenic antiepileptic drugs), quality of life (if the patient is frightened by or unable to attend hygienically to her menses), or the treatment of menorrhagia or dysmenorrhea. A case-control study in Scandinavia compared women with and without ID who were patients in a gynecological practice. "Typical" women were much more likely to list pregnancy, abortion, or dilation and curettage as their reason for the visit; women with ID were more likely to be there for therapeutic amenorrhea. ${ }^{9}$ More than half $(67 \%)$ of the women with ID in this study sought therapeutic amenorrhea at some point in their lives. More recent studies discuss this therapy in light of caregivers' ethical responsibilities to the women in their care and have advocated the "least restrictive option." Least restriction involves a less invasive option that is more 
likely to be reversible and preserve the patient's options in terms of fertility. Least restriction implies using medications or progestin intrauterine device over endometrial ablation or surgery. ${ }^{10}$ In fact, one prospective cohort study observed that of 107 women with ID, only 2 eventually required surgical management of their menstrual/contraceptive issues. ${ }^{11}$ In recent years physicians have attempted to manage women with ID respectfully with regard to their potential reproductive rights, choosing less restrictive, more reversible options for contraception and therapeutic amenorrhea.

Researchers note that primary care physicians have not focused on menstrual issues for women with ID-one survey of community-dwelling women noted that $40 \%$ of the women surveyed were not asked about their gynecological needs by their primary care physician. ${ }^{12}$ Another researcher investigated the commonly held belief that women with Down syndrome either have amenorrhea or are infertile. In this survey of an admittedly small number of women with Down syndrome and agematched controls, the age at menarche, cycle length, and duration of menses were indistinguishable between the 2 groups, indicating that women with Down syndrome are likely ovulating at comparable rates to women without Down syndrome. ${ }^{13}$

The Australian Society of Pediatric and Adolescent Gynecology published a consensus statement on the clinical management of menstrual issues in women with ID in 2003. ${ }^{14}$ The statement advocates a stepwise management to menstrual difficulties in women with ID, starting with the least invasive options and progressing to therapies that require more complex forms of consent.

\section{Cervical Cancer Screening}

Many primary care physicians question the indication for yearly Papanicolaou tests in adult women with ID given the difficulties of the examination. For many women with ID, the experience of the gynecological examination is painful, frightening, may call to mind past episodes of abuse, and may result in increased fear about visiting the doctor's office-all undesired outcomes for a physician who has worked hard to gain a patient's trust. Only recently has there been sufficient evidence suggesting that it is safe to omit the annual Papanicolaou test, although the numbers of women with ID actually being screened is approximately $15 \% .{ }^{15}$ Two cohort studies in the past decade examined the largest ( $\mathrm{n}>300)$ groups of women with ID to date residing in institutional settings and found that the number of abnormal Papanicolaou smears was extremely low, ${ }^{16,17}$ although it should be noted that the sample was biased toward lower-risk (institutionalized) women. As more women grow up and socialize in their communities, their opportunities for consensual sexual activities increase. Based on our review of the literature, we recommend individualizing the interval for screening to each patient's risk, ${ }^{18}$ keeping in mind that women with ID may be less able to accurately relate their sexual history. In such cases, details about the patient's environment and known history may be helpful. For example, a woman living in a highly supervised, single-sex environment since childhood is unlikely to be sexually active and might be a good candidate for less-frequent screening and/or human papillomavirus (HPV) screening (see below).

Techniques for performing the examination in women with both physical ${ }^{19}$ and intellectual disabilities exist for those women considered at sufficient risk for regular exams. For women with ID, several factors have been found to be helpful, including prolonged preparation for the examination, communication with the provider, explanation appropriate to the patient's level of understanding, and support. ${ }^{20}$ Protocols have been developed which focus on stepwise relaxation ${ }^{21}$ and deep breathing exercises; using a small, warmed speculum may also be helpful. In some cases, it may be necessary to premedicate with benzodiazepines ${ }^{22}$ or use conscious sedation ${ }^{23}$ to complete the gynecological examination. Currently, no consensus exists as to which methods are best tolerated and least risky, and different methods may be appropriate for different women.

Although the feasibility and accuracy of HPV screening compared with traditional cytology for the detection of cervical cancer ${ }^{24}$ has not been studied in women with ID, it may prove to be an alternative form of less-frequent screening for these lower-risk women. The American Cancer Society (ACS) and American College of Obstetrics \& Gynecology (ACOG) recommend less frequent screening (every 3 years) for women with negative HPV screening and a normal Papanicolaou smear $^{25}$; this recommendation is appropriate for many women with ID. Finally, it should be noted that there may be reasons other than cervical cancer screening to do a gynecological examination- 
for example, the evaluation of pelvic pain or uterine/adnexal pathology. If cervical cancer screening is not a priority (for example, in women who have never been sexually active), then we recommend considering bimanual examination or pelvic ultrasound instead of speculum exams to evaluate potential gynecological problems, as they may be better tolerated. If the clinician needs to screen the patient for sexually transmitted infections other than HPV, urine testing provides a less invasive way to accomplish this ${ }^{26}$ and is likely to be more acceptable for the patient.

\section{Contraception}

There are many reasons to consider contraception for women with ID. Women with ID may not desire or may not be good candidates for pregnancy if they chronically take teratogenic medications (such as some antiepileptic drugs). Caretakers may worry about the ability of a woman with ID to understand pregnancy, to care for herself during a pregnancy, or to care for a child. Investigators in Brussels $^{27}$ surveyed nearly 400 women with ID to determine what method, if any, they used for contraception and what social and medical factors influenced their choice of method. The majority of women surveyed were using contraception (59\%) with the most common method being surgical sterilization (22\%), followed by oral contraceptives and Depo-Provera (each 18\%). Factors influencing their choice of method were almost entirely environmental and focused on the setting in which they lived (single-sex or coed, with or without rules allowing sexual intercourse and/or requiring contraception). The results of this study suggest that at least in Brussels, the contraception decisions of women with ID may be made based on the rules of the setting in which they live. A recent study of the use of antiepileptic drugs in women with $\mathrm{ID}^{28}$ noted that some of these drugs (eg, carbamazepine, phenytoin, and valproate) were teratogenic and interfered with the efficacy of oral contraceptives, making these medications an important element of the medical history to consider when treating women with ID.

The question of whether someone with ID would make a "good parent" can be quite subjective and has been the focus of ethical discussions for years. The current foundations of ethical thinking regarding contraception for women with ID are summarized at the end of this article.
The Australian Society of Pediatric and Adolescent Gynecology consensus statement in regard to menstrual issues ${ }^{14}$ and a special issue of the Contraception Report ${ }^{29}$ describe clinical guidelines for contraceptive management, social and psychological implications of contraceptive counseling, and the ethical issues surrounding birth control for women with ID.

\section{Breast Cancer Screening}

Ethnic, racial, and socioeconomic disparities in breast cancer screening present major challenges to the American health care system. Disparities in screening for women with physical ${ }^{30-32}$ and intellectual disabilities also exist and have received less attention. Only approximately one-third of eligible women with ID were screened for breast cancer in 2 regional samples from England ${ }^{33}$ and Australia. ${ }^{34}$ In the Australian study, women were less likely to be screened if they were unmarried, lived in an urban setting, had severe ID, or had concomitant physical disabilities. Australian investigators who interviewed caregivers about ways to increase mammography in women with ID concluded that many barriers to mammography seemed insurmountable (especially physical barriers for patients with comorbid physical disabilities). They suggested alternative methods of screening (such as clinical breast examination)—-methods which lack sufficient evidence for their use as screening tools in the general population. ${ }^{35}$

Rates of breast cancer in women with ID reported in 2 large cohort studies are the same as or lower than the general population. ${ }^{36,37}$ However, women with ID are living longer and because the risk of breast cancer rises with each decade of life, ${ }^{38}$ the rates of breast cancer in women with ID will probably rise. An interesting note is that women with Down syndrome seem to have extremely low rates of breast cancer, ${ }^{39}$ so low that some have advocated simply not screening them, as the risk conferred by the radiation of mammography is probably higher. ${ }^{40}$

There is a need for further research on breast cancer screening for women with ID in the United States, focusing on cancer incidence, factors associated with underuse of mammography for women with ID, and guidelines for determining who should and should not be screened. There is some current controversy about clinical management (mammography versus clinical breast examination 
Table 2. Summary of Clinical Guidelines and Resources

\begin{tabular}{|c|c|c|c|}
\hline Topic & Clinical Guidelines & Available Resources & SORT \\
\hline Menstrual disorders & $\begin{array}{l}\text { Therapeutic amenorrhea may be } \\
\text { indicated; stepwise management and least } \\
\text { invasive options recommended }\end{array}$ & $\begin{array}{l}\text { Consensus statement on menstrual and } \\
\text { contraceptive management }{ }^{13}\end{array}$ & $\mathrm{C}$ \\
\hline Cervical cancer screening & $\begin{array}{l}\text { Interval for screening should be } \\
\text { individualized to patient; consider } \\
\text { sedation, relaxation techniques }\end{array}$ & & B \\
\hline Contraception & $\begin{array}{l}\text { Can be influenced by residential setting } \\
\text { and individual needs; caution regarding } \\
\text { antiepileptic drugs* }\end{array}$ & $\begin{array}{l}\text { Consensus statement }{ }^{13} \text { and issue of } \\
\text { Contraception Report }{ }^{26}\end{array}$ & $\mathrm{C}$ \\
\hline Breast cancer screening & $\begin{array}{l}\text { Follow established guidelines for } \\
\text { mammography }\end{array}$ & & $\mathrm{C}$ \\
\hline Osteoporosis & $\begin{array}{l}\text { High prevalence in women with ID; early } \\
\text { and more frequent screening }\end{array}$ & 13 references; see refs. 50 and 52 & A \\
\hline
\end{tabular}

*Antiepileptic drugs can be (1) more likely to interact with oral contraceptives and (2) more likely to have teratogenic effects that would prompt initiation of contraception.

SORT, strength of recommendation taxonomy; ID, intellectual disability.

or ultrasound) as we await better evidence-based guidelines, but several consensus statements ${ }^{41,42}$ and a prior review on screening ${ }^{18}$ advocate following the same guidelines as for the general population.

\section{Osteoporosis}

The increased prevalence of osteoporosis among all people with intellectual disabilities is well-documented. ${ }^{43-48}$ Relatively fewer studies have investigated the risk factors for low bone density within the population of adults with ID-for example, epilepsy $^{49}$ or Down syndrome. ${ }^{50}$ Adults with ID who live in group homes have high facture rates compared with the general population. ${ }^{51}$ Two researchers reported the specific risk factors associated with the highest rates of osteoporosis and osteopenia among adults with ID. ${ }^{52,53}$ Both studies conclude that nonambulation and anticonvulsant use are important factors associated with low bone density, although the smaller study ${ }^{53}$ commented that the anticonvulsant risk was highest in postmenopausal women. Down syndrome and low peak bone mass were listed as important risk factors in one review, ${ }^{52}$ whereas ethnicity was felt to be important in the smaller study, with Hispanic and Caucasian women at relatively higher risk.

To date, no clinical trials have determined the best practice for screening adults with ID for osteoporosis. However, early screening for osteoporosis (see Table 2), especially among patients who are nonambulatory or taking anticonvulsants, is advocated. ${ }^{18,41,42,54,55}$

\section{Discussion: Ethical and Legal Decision Making}

Nowhere are the ethical and legal considerations of treatment decisions more important, or more complex, than in the provision of primary care for women with ID. Especially in relation to sexuality and reproductive health, decisions historically were based in public policy deeply influenced by discrimination and pervasive stereotypes. New public policy, ethics, and federal and state laws now guide practice decisions with women with ID. Critical to these decisions are issues relating to informed consent and sterilization.

Many women with ID can give informed consent, that is, approval for treatment that is given without coercion and made autonomously, competently, and with knowledge, and some cannot. ${ }^{56}$ The ability of women with ID to give informed consent varies widely and depends on characteristics of the individual, the decision to be made, the person's living environment, and attitudes of the health provider. Wehmeyer and Bolding ${ }^{57}$ noted that proxy decision making is more often made when the individual lives in a congregate living situation where self-determination and autonomy may be curtailed. Proxy decision making is highly prevalent in decisions relating to the reproductive health of women with disabilities in which negative attitudes about the sexuality of people with ID influence a woman's access to sexual health services. ${ }^{58}$ Competency is a legal issue. Women with ID are presumed competent unless that presumption 
has been abridged by a court; parents, for example, cannot make health decisions for their adult child with disabilities unless designated as a decisionmaker by the court.

The procedure of sterilization is impacted by issues of informed consent that have paid little attention to the decision-making capabilities of women with ID, their ability to take care of children, their feelings or their interests, and by the mistaken belief that sterilization will change inappropriate sexual behavior. ${ }^{59}$ We have moved from a society in which as many as 37 states had compulsory sterilization laws for people with disabilities to a nation that values the most intimate decisions of all people and often requires court approval when the individual is unable to consent. Introduction of birth control issues at puberty, use of the least intrusive birth control methods available, and review of state laws on consent and sterilization are recommended.

\section{Conclusion}

With greater social inclusion, people with ID enjoy an increased presence in their communities, including in primary care practices. Without specific recommendations supported by evidence, their care may be influenced by providers' individual assumptions about them, which may or may not be valid. This problem may be particularly true of the health issues of women with ID, because the management of these issues often relies on the patient's active participation in her care.

Currently, few consensus statements exist regarding the best practices for selected women's health issues and screening for people with ID. ${ }^{14,18,29,41,42}$ In the absence of primary US data, these consensus statements and data from other countries can serve as our clinical guidelines. More research is needed to gather data about the diagnosis and management of adult women with ID in the United States that can inform recommendations for their primary care. There is a need for increased research and funding directed at the medical care of this growing and underserved segment of our population.

\section{References}

1. Luckasson R, Coulter DL, Polloway EA, et al. Mental retardation: definition, classification and systems of support. Washington, DC: American Association of Mental Retardation; 2002.
2. Larson SA, Lakin KC, Anderson L, Kwak N, Lee $\mathrm{JH}$, Anderson D. Prevalence of mental retardation and developmental disabilities: estimates from the 1994/1995 National Health Interview Survey Disability Supplements. Am J Ment Retard 2001;106(3): 231-52.

3. Edgerton RB, Gaston MA, Kelly H, Ward TW. Health care for aging people with mental retardation. Ment Retard 1994;32(2):146-50.

4. US Department of Health and Human Services. Healthy People 2010: Understanding and Improving Health. 2nd ed. Washington, DC: US Government Printing Office; November 2000.

5. US Public Health Service. Closing the Gap: A National Blueprint for Improving the Health of Individuals with Mental Retardation. Report of the Surgeon General's Conference on Health Disparities and Mental Retardation. Washington, DC; February 2001.

6. The Boston Women's Health Collective. The new our bodies, our selves. New York: Simon and Schuster; 1984.

7. Curlin FA, Lawrence RE, Chin MH, Lantos JD. Religion, conscience and controversial clinical practices. N Engl J Med 2007;356(6):593-600.

8. Walsh PN, Heller T, editors. Health of women with intellectual disabilities. Malden (MA): Blackwell Publishing USA; 2002.

9. Huovinen KJ. Gynecological problems of mentally retarded women. Acta Obst Gyn Scand 1993;72: $475-80$.

10. Wingfield M, Healy DL, Nicholson A. Gynecological care for women with intellectual disability. Med J Australia 1994;10:536-8.

11. Grover SR. Menstrual and contraceptive management for women with an intellectual disability. Med J Aust 2002;176(3):108-10.

12. Kopac CA, Fritz J, Holt RA. Gynceologic and reproductive services for women with developmental disabilities. Clin Exc for Nurs Prac 1998;2(2):88-95.

13. Goldstein H. Menarche, menstruation, sexual relations and contraception of adolescent females with Down syndrome. Eur J Obgyn and Repro Bio 1988; 27:343-9.

14. Atkinson E, Bennett MJ, Dudley J, et al. Consensus statement: Menstrual and contraceptive management in women with an intellectual disability. Aust New Zeal J Obst Gynec 2003;43:109-10.

15. Stein K, Allen N. Cross sectional survey of cervical cancer screening in women with learning disability. Br Med J 1999;318(7184):641.

16. Quint E, Elkins T. Cervical cytology in women with mental retardation. Obstet Gyn 1997;89(1):123-6.

17. Jaffe JS, Timell AM, Eisenberg MS, Chambers JT. Low prevalence of abnormal cervical cytology in an institutionalized population with intellectual disability. J Intell Disabil Res 2002;46(Pt 7):569-74.

18. Wilkinson J, Culpepper L, Cerreto MC. Primary 
care screening tests for adults with intellectual disabilities. J Am Board Fam Med 2007;20(4):399-407.

19. Welner SL, Foley CC, Nosek MA, Holmes A. Practical considerations in the performance of physical examinations on women with disabilities. Obs Gyn Survey 1999;54(7):457-62.

20. Broughton S, Thomson K. Women with learning disabilities: risk behaviors and experiences of the cervical smear test. J Adv Nurs 2000 Oct;32(4):90512.

21. Prevatt B. Gynecological care for women with mental retardation. J Obstet Gynec Neonatal Nurs 1998; 7(3):2516.

22. Messinger-Rapport BJ, Rapport D. Primary care for the developmentally disabled adult. J Gen Int Med 1997;12(10):629-36.

23. Jaffe JS. Conscious sedation for the performance of gynecologic examination of individuals with intellectual disability. Conn Med 2005;69(5):267-9.

24. Ronco G, Segnan N, Giorgi-Rossi P, et al. Human papilloma virus testing and liquid-based cytology: results at recruitment from the new technologies for cervical cancer randomized controlled trial. J Natl Cancer Inst 2006;98(11):765-74.

25. Centers for Disease Control. Summary of HPV screening recommendations. Available at www.cdc.gov/std/hpv/ScreeningTables.pdf. Accessed 5 November 2007.

26. Centers for Disease Control. Sexually transmitted diseases treatment guidelines, updated 2002. Available at www.cdc.gov/mmwr/preview/mmwrhtml/ rr5106a1.htm. Accessed 5 November 2007.

27. Servais L, Jacques D, Leach R, et al. Contraception of women with intellectual disability: prevalence and determinants. J Intellect Disabil Res 2002;46(Pt 2): 108-19.

28. Kaplan PW. Reproductive health effects and teratogenicity of antiepileptic drugs. Neurology 2004;63(10 Suppl 4):513-23.

29. Reproductive health care for the mentally handicapped. In: Grimes D, editor. Contraception Report 1997;8(4):4-11. Available at www.contraceptiononline.org/contrareport/pdfs/08_04.pdf. Accessed 20 June 2007.

30. Caban ME, Nosek MA, Graves D, Esteva FJ, McNeese M. Breast carcinoma treatment received by women with disabilities compared with women without disabilities. Cancer 2002;94(5):1391-6.

31. Schootman M, Jeffe DB. Identifying factors associated with disability-related differences in breast cancer screening (United States). Cancer Cause Control 2003;14(2):97-107.

32. Nosek MA, Howland CA. Breast and cervical cancer screening among women with physical disabilities. Arch Phys Med Rehab 1997;78(12 Suppl 5):39-44.

33. Davies N, Duff M. Breast cancer screening for older women with intellectual disability living in group homes. J Intellect Disabil Res 2001;45(Pt 3):253-7.
34. Sullivan SG, Glasson EJ, Hussain R, et al. Breast cancer and the uptake of mammography screening services by women with intellectual disabilities. Prev Med 2003;37(5):507-12.

35. Sullivan SG, Slack-Smith LM, Hussain R. Understanding the use of breast cancer screening services by women with intellectual disabilities. Soz Praventivmed 2004;49(6):398-405.

36. Sullivan SG, Hussain R, Threlfall T, Bittles AH. The incidence of cancer in people with intellectual disabilities. Cancer Cause Control 2004;15:1021-5.

37. Patja K, Eero P, Iivanainen M. Cancer incidence among people with intellectual disability. J Intell Disabil Res 2001;45(Pt 4):300-7.

38. Kelsey JL, Gammon MD. The epidemiology of breast cancer. CA Cancer J Clin 1991;41(3):146-65.

39. Yang O, Rasmussen SA, Friedman JM. Mortality assoc with Down Syndrome in the United States 1983-97: a population-based study. Lancet 2002 Mar 23;359(9311):1019-25.

40. Satge D. Breast cancer screening guidelines should be adapted in Down syndrome. Br Med J 2002; 324(7346):1155.

41. Massachusetts Department of Mental Retardation. Preventive health recommendations for adults with mental retardation. Available at www.mass.gov/Eeohhs2/docs/dmr/health_screening_brochure.pdf. Accessed 27 February 2007.

42. Sullivan WF, Heng J, Cameron D, et al. Consensus guidelines for primary health care of adults with developmental disabilities. Can Fam Phys 2006;52(11):1410-18.

43. Fisher K, Kettl P. Aging with mental retardation: increasing population of older adults with MR require health interventions and prevention strategies. Geriatrics 2005;60(4):26-9.

44. Lohiya GS, Tan-Figueroa L, Iannucci A. Identification of low bone mass in a developmental center: finger bone mineral density measurement in 562 residents. J Am Med Direct Assoc 2004;5(6):371-6.

45. Jaffe JS, Timell AM, Gulanski BI. Prevalence of low bone density in women with intellectual disabilities. J Clin Densitometry 2001;4(1):25-9.

46. Wagemans AM, Fiolet JF, van der Linden ES, Menheere PP. Osteoporosis and intellectual disability: is there any relation?. J Intell Disabil Res 1998;42(Pt 5):370-4.

47. Center J, Beange H, McElduff A. People with mental retardation have an increased prevalence of osteoporosis: a population study. Am J Ment Retard 1998;103(1):19-28.

48. Aspray TJ, Francis RM, Thompson A, Quilliam SJ, Rawlings DJ, Tyrer SP. Comparison of ultrasound measurements at the heel between adults with mental retardation and control subjects. Bone 1998;22(6):665-8.

49. Churesigaew S, Ruvalcaba RH, Kelley VC. Epilepsy and abnormal calcium metabolism in institutional- 
ized mentally retarded patients. Am J Ment Defic 1975;79(6):738-41.

50. Schrager S. Osteoporosis in women with disabilities. J Wom Health 2004;13(4):431-7.

51. Lohiya GS, Crinella FM, Tan-Figueroa L, Caires S, Lohiya S. Fracture epidemiology and control in a developmental center. West J Med 1999;170(4):203-9.

52. Schrager S. Epidemiology of osteoporosis in women with cognitive impairment. Ment Retard 2006;44(3): 203-11.

53. Jaffe JS, Timell AM, Elolia R, Thatcher SS. Risk factors for low bone mineral density in individuals residing in a facility for the people with intellectual disability. J Intell Disabil Res 2005;49(Pt 6):457-62.

54. Tyler CV, Snyder CW, Zyzanski S. Screening for osteoporosis in community-dwelling adults with mental retardation. Ment Retard 2000;38(4):316-21.

55. Schrager S, Kloss C, Ju AW. Prevalence of fractures in women with intellectual disabilities: a chart review. J Intell Disabil Res 2007;51(Pt 4):253-9.

56. Kaplan C, Richman S. (2006) Informed consent and the mentally challenged patient in Ob-Gyn care. Contemporary OB/GYN 2006 October 1. Available at http://www.modernmedicine.com/ modernmedicine/article/

articleDetail.jsp?ts $=1186497627675$ \&id $=378053$ ). Accessed 26 June 2007.

57. Wehmeyer ML, Bolding N. Enhanced self-determination of adults with intellectual disability as an outcome of moving to community-based work or living environments. J Intellect Disabil Res 2001;45:37183.

58. Aunos M, Feldman MA. Attitudes towards sexuality, sterilization and parenting rights of persons with intellectual disabilities. J Appl Res Intellect Disabil 2002;15:285-96

59. AAP Committee on Bioethics. Sterilization of minors with developmental disabilities. Pediatrics 1999; 104(2):337-40. 